\title{
Routine Diagnosis of Mycoplasma pneumoniae the Infection
}

\section{Mycoplasma pneumoniae Enfeksiyonu Rutin Tanısı}

\author{
Mustafa Hacımustafaoğlu ${ }^{1}$ \\ ${ }^{1}$ Division of Infectious Diseases, Department of Pediatrics, Uludag Üniversity School of Medicine, Bursa, Turkey
}

\section{Dr. Funda Aydemir}

Question: We know that Mycoplasma pneumoniae infection is one of the common causes of lower respiratory tract infections. What is the reliable and priority examination you would recommend in routine diagnosis?

\section{Answer (Dr. Mustafa Hacımustafaoğlu)}

Mycoplasma pneumoniae infection, especially in children $>5$ years old, leads to upper and lower respiratory tract infections, including pharyngitis, with long lasting cough not responding to drugs such as penicillin and cephalosporin. Cough initially becomes non-productive, then productive and may last 3-4 weeks and may be accompanied by twheezingle while constitutional symptoms may be at the forefront, and physical examination findings are relatively less.

Mycoplasma's laboratory sensitivity is problematic, so it should be applied if it affects the treatment. In ambulatory patients, laboratory testing may generally not be performed because the response to empirical treatment with clinical prediction is generally positive. Routine hemogram in mycoplasma is nonspecific. Normally, there is no place for throat culture in the diagnosis of pneumonia. Mycoplasma is not usually found in the throat as the element of commensal or normal flora. However, it may remain in the respiratory system for a long time after infection and may reflect prolonged colonization in this sense. Therefore, in a patient who is thought to have pneumonia, its presenting in the throat culture may be the sign of a cause with clinical findings. Throat culture requires a special media and a period of 2-3 weeks, so it is generally not recommended for acute diagnosis. In addition, culture cannot be performed anywhere and the laboratory should be informed before culture is sent. Throat or nasopharyngeal specimens can be diagnosed by PCR. PCR can also be multiplex PCR. IDSA, recommends the use of PCR or serology in M. pneumoniae laboratory diagnosis. As mentioned above, both culture and PCR may remain positive even after weeks of acute infection despite of the treatment. Antibodies checked by serologically different methods can be used. They are the antibodies in the $\operatorname{lgM}$ structure against erythrocyte antigens of cold agglutinin and arise $50 \%$ of cases, especially with higher titers (usually $>1 / 128$ ) in patients with pneumonia. However, it is not recommended for diagnosis in children. In addition, bedside tube tests of cold agglutinin are not recommended for diagnosis.

Serologically, M. pneumoniae specific IgG and IgM are used in the diagnosis. IgM positivity shows active infection but does not become positive during the first 7-9 days of symptoms. IgM can peak at 3-6 weeks and remain positive for 2-3 months. The increase of lgG in the double serum sample is also important in the diagnosis, confirms diagnosis, but not in the 
acute diagnosis and not quiding the treatment. In the diagnosis of M. pneumoniae, it may be used in the antigen diagnostic test with PCR or EIA in respiratory samples. Antigen diagnostic test can detect $10^{4} \mathrm{CFU} / \mathrm{ML}$ antigens (available in most of the infections).

In summary; the treatment of M. pneumoniae infection is performed empirically in the presence of clinical symptoms in children. In cases laboratory diagnosis is necessary, PCR (at the time of clinical findings) or serology (lgG elevation in the paired serum samples) is recommended in the nasopharyngeal specimen.

\section{References}

1. American Academy of Pediatrics. Mycoplasma pneumoniae and Other Mycoplasma Species Infecitions. In: Red Book: 2015 Report of the Committee on Infectious Diseases, 30th, Kimberlin DW, Brady MT, Jackson MA, Long SS (eds). Elk Grove Village, IL: American Academy of Pediatrics, 2015:568-71.

2. Baron EJ, Miller JM, Weinstein MP, et al. A guide to utilization of the microbiology laboratory for diagnosis of infectious diseases: 2013 recommendations by the Infectious Diseases Society of America (IDSA) and the American Society for Microbiology (ASM). Clin Infect Dis 2013;57:e22-e121.
3. Bradley JS, Byington CL, Shah SS, et al. The management of community-acquired pneumonia in infants and children older than 3 months of age: clinical practice guidelines by the Pediatric Infectious Diseases Society and the Infectious Diseases Society of America. Clin Infect Dis 2011;53:e25-76.

4. Marmion BP, Williamson J, Worswick DA, et al. Experience with newer techniques for the laboratory detection of Mycoplasma pneumoniae infection: Adelaide, 1978-1992. Clin Infect Dis 1993;17(Suppl 1):90-9.

5. Mycoplasma pneumoniae infection in children. https://www.uptodate. com (Erişim tarihi: Temmuz 2018).

6. Tay YK, Huff JC, Weston WL. Mycoplasma pneumoniae infection is associated with Stevens-Johnson syndrome, not erythema multiforme (von Hebra). J Am Acad Dermatol 1996;35:757-60. 